\title{
ANÁLISE DE SITUAÇÕES GEOGRÁFICAS: NOTAS SOBRE METODOLOGIA DE PESQUISA EM GEOGRAFIA.
}

\author{
ANALYSIS OF GEOGRAPHIC SITUATIONS: NOTES ON \\ METHODOLOGY AND RESEARCH IN GEOGRAPHY
}

ANÁLISIS DE SITUACIONES GEOGRÁFICAS: NOTAS SOBRE METODOLOGÍA DE INVESTIGACIÓN EN GEOGRAFÍA

\section{Márcio Antonio Cataia}

Doutor em geografia pela Faculdade de Filosofia, Letras e Ciências Humanas da Universidade de São Paulo (USP). Pós-doutorado pela Université Paris III - Institut des Hautes Études de l'Amerique Latine. Docente do Departamento de Geografia do Instituto de Geociências da UNICAMP.

Endereço: Rua João Pandiá Calógeras, 51 - Barão Geraldo - Campinas - CEP: 13083-870 - São Paulo. Tel: +55 (19) 3521-4784

Email: cataia@ige.unicamp.br

\section{Luis Henrique Leandro Ribeiro}

Doutor em geografia pelo Instituto de Geociências da Universidade Estadual de Campinas. Pósdoutorando na Faculdade de Formação de Professores da Universidade Estadual do Rio de Janeiro. Programa de Pós-Graduação em Geografia, da Universidade do Estado do Rio de Janeiro (FFP/UERJ). Endereço: Rua Francisco Portela, 1470 - Patronato - São Gonçalo- CEP: 24435-005 - Rio de Janeiro. Tel: +55 (21) 3705-2227 - ramal 246

E-mail: luis.ribeiro@yahoo.com.br

\section{RESUMO}

Objetivamos resgatar o conceito de situação geográfica apresentando uma sistematização ao explanar sobre sua força teórico-metodológica. Situações geográficas dizem respeito aos nexos entre horizontalidades e verticalidades nos lugares, precipitados de impulsos globais por um lado e, por outro, cristalizações de heranças de usos populares que se atualizam. Empiricamente realizamos pesquisa sobre a incorporação de plantas medicinais e fitoterápicos pelo Sistema Único de Saúde (SUS), buscando relatar como os lugares são organizados para constituir situações geográficas únicas. Abordamos as noções e sentidos do conceito de situação buscando identificar alguns traços filosóficos gerais que informam e iluminam o conceito de situação geográfica. Sistematizamos a produção geográfica clássica e contemporânea, não almejando, evidentemente, esgotar o tema. E apresentamos a operacionalização metodológica que permitiu identificar oito situações geográficas em nossa pesquisa sobre o SUS realizada em distintas regiões do Brasil.

PALAVRAS-CHAVE: situação geográfica; uso do território; Sistema Único de Saúde; plantas medicinais. 


\begin{abstract}
We aimed to retrieve the concept of geographic situation through a systematization, offering an explanation of its theoretical-methodological strength. Geographic situations relate to the links between horizontal and vertical aspects in places, precipitated, on the one hand by global impulses, and on the other by crystallized inheritances of selfupdating popular uses. In empirical terms we conducted a study into the incorporation of medicinal plants and herbal remedies by the Unified Health System (SUS), aiming to report how places are organized to constitute unique geographic situations. We address the notions and meanings of the concept of situation to identify some general philosophical traits that inform and enlighten the concept of geographic situation. We systematized classic and contemporary geographic production, without intending to exhaust the theme. Finally, we present the methodological operationalization that enables the identification of eight geographic situations in our study about the SUS in different regions of Brazil.
\end{abstract}

KEYWORDS: geographic situation; use of the territory; Unified Health System; medicinal plants.

\title{
RESUMEN
}

Se objetiva rescatar el concepto de situación geográfica presentando una sistematización en la exposición de su fuerza teórico-metodológica. Por situación geográfica nos referimos a los nexos entre horizontalidad y verticalidad en los lugares, precipitados de impulsos globales, por un lado, y de cristalizaciones de herencias de usos populares que se actualizan, por otro. Empíricamente se investiga la incorporación de plantas medicinales y preparaciones fitoterapéuticas por el Sistema Único de Salud (SUS), buscando relatar cómo se organizan los lugares para constituir situaciones geográficas únicas. Se abordan las nociones y sentidos del concepto de situación buscando identificar algunos rasgos filosóficos generales que informan e iluminan el concepto de situación geográfica. Se sistematiza la producción geográfica clásica y contemporánea, sin aspirar, evidentemente, a agotar el tema. Se presenta la operacionalización metodológica que permitió identificar ocho situaciones geográficas en la investigación sobre el SUS, realizada en distintas regiones de Brasil.

PALABRAS CLAVE: situación geográfica; uso del territorio; Sistema Único de Salud; plantas medicinales. 


\section{INTRODUÇÃO: A IMPORTÂNCIA DO CONCEITO DE SITUAÇÃO GEOGRÁFICA}

Este artigo objetiva recuperar o conceito de situação geográfica como já fizeram alguns autores e, a partir de pesquisa realizada sobre o Sistema Único de Saúde (SUS), apresentar uma sistematização do conceito e explanar sobre sua operacionalidade e força teórica.

O conceito de situação geográfica é pertinente para analisar e articular variáveis, agentes e processos em diversas escalas a partir de um foco particular. Enquanto nó de verticalidades e horizontalidades, manifestação provisória do movimento de totalização (Silveira, 1999), a situação geográfica vincula universalidade e particularidade.

Síntese teórica que permite estabelecer nexos entre mundo, formação socioespacial e lugar, a situação geográfica substantiva o princípio teórico de que o uso do território (Santos, 1999b) tem existência nos lugares. Como lembra Kahil (2010, p.477), "o lugar não é uma parte do mundo" /.../ mas o /.../ "mundo em movimento - um movimento dinamizado pelos eventos - um movimento permanente de metamorfose do real-abstrato em real-concreto, e vice-versa, dito de outra maneira, a totalidade em perpétuo movimento". O território usado é a dimensão política do espaço geográfico e "ponte estrategicamente posicionada entre a teoria crítica do espaço e a ação política” (Ribeiro, 2003, p.29).

Nesse sentido, a situação geográfica é um recurso metodológico relevante para analisar os usos do território pelos diversos e desiguais agentes, como o próprio termo indica: sítio mais ação. Conceito que permite lidar com a categoria geográfica de espaço enquanto híbrido de materialidades e ações, "um conjunto indissociável, solidário e também contraditório, de sistemas de objetos e sistemas de ações, não considerados isoladamente, mas como o quadro único no qual a história se dá" (Santos, 1999a, p.51).

O sítio, usado, praticado e herdado, condiciona a sociedade na medida em que é ma-

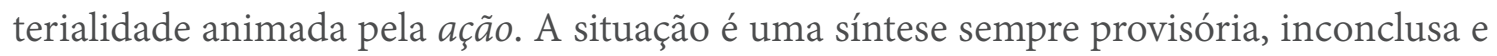
aberta, expressão de "todo o peso do passado e da mudança que se impõe" (Zaoual, 2010, p.27). Processo pelo qual "o tempo empiricizado entra como condição de possibilidade e a entidade geográfica entra como condição de oportunidade” (Santos, 1997, p.36).

Ao se posicionar estrategicamente entre a teoria social crítica e a ação política o conceito de situação geográfica recompõe a relação sujeito e objeto de pesquisa nos termos da reflexividade. Aqui entendida como aquela consciência que percebe (e que sempre está presente na criação de uma ciência social) e, mais ainda, que se questiona enquanto consciência que percebe. Padrão de reflexividade e de questionamento da consciência que percebe 
que podem nos ajudar no afastamento dos riscos de tornar a geografia uma disciplina de cunho positivista, porque supostamente neutra e isenta quando praticada (Ribeiro, 2002).

Para essa discussão teórica e prática o texto está dividido em três partes, mais as considerações finais. Na primeira parte abordamos as noções e sentidos do termo e do conceito de situação em outras áreas. Longe de esgotar o tema pretendemos sistematizar alguns traços filosóficos gerais compartilhados e que também informam e iluminam o conceito de situação geográfica, tratado na segunda parte. Na terceira parte apresentamos as oito situações geográficas identificadas a partir de resultados de pesquisa realizada. O texto é encerrado com as considerações finais.

\section{SITUAÇÃO: NOÇÕES E SENTIDOS FUNDADORES}

$\mathrm{O}$ conceito de situação não nasceu com a geografia e é tão antigo quanto a filosofia aristotélica. Em Aristóteles a situação é equiparada a um estado ou a uma das categorias que designa a posição de um objeto, o modo como está, como deitado, sentado etc. No existencialismo, a situação é central para a constituição da condição humana, pois em sua existência o homem é colocado sempre em um contexto preestabelecido, em um mundo que não foi construído por ele e que o antecede, que constitui o homem como tal e em relação ao qual forma sua liberdade e sua identidade (Japiassu; Marcondes, 2001).

Sempre tecido de modo imperfeito o conhecimento situado, porque de caráter contextualizado, não reclama ser absoluto e privilegiado, mas prima pelo princípio de que sempre há caminhos distintos e contrastantes para conhecer o mundo, igualmente parcial e igualmente contestável. Logo, a situação implica uma compreensão da realidade responsável por possibilitar uma prática política, essa seria uma contribuição vital que geógrafos podem fazer, sobretudo considerando que descrições da realidade ajudam em boa medida a constituir essa própria realidade (Merrifield, 1995).

Segundo Auat (2011), a filosofia deve ancorar seu sentido na situacionalidade de toda razão e de todo saber. Uma estratégia conceitual para compreender a universalidade de outro modo que não a universalidade abstrata e imperial resultante da imposição unívoca de um particular idealizado. O pensamento situado não é uma análise descritiva de particularismos isolados, mas uma abertura à consideração de contextos cada vez mais amplos para a compreensão da situação politicamente particular ocupada. Para Auat (2011), o homem não tem outro remédio senão viver em situação, ou seja, ser no mundo com outros homens, pois que todo pensamento é expressão de uma determinada situação e superação desta. O pensamento situado amplifica a experiência cotidiana e histórica ao singularizar a problemática universal. larizar a problemática universal. 
Ao opor o homo situs - isto é, o homem vivo e concreto cujo comportamento está enraizado num território - à concepção hegemônica e reducionista do homo oeconomicus, Zaoual (2010) destaca o imperativo do homem em seu contexto. A perspectiva pluralista da teoria dos sítios se baseia numa racionalidade situada que parte da consideração dos diversos contextos e escalas de ação dos agentes. A incompletude dos conceitos e indicadores se deve à diversidade das situações. A ciência, como o pensamento humano em geral, sempre buscou reconduzir o múltiplo à unidade visando tornar o mundo compreensível. Esse exercício carrega deslizes perigosos e generalizações abusivas, por isso a teoria do homo situs pode ser um caminho para atenuar os excessos de afastamento entre o observável e o conceitual.

Com efeito, a experiência revela que o homo situs retira suas justificativas comportamentais de universos complexos. Estes últimos têm um caráter mestiço e uma natureza dinâmica. Este hibridismo encontra sua justificativa nas misturas que se produzem entre o sítio como organismo aberto e fechado, já que é seletivo das mudanças, e o meio ambiente, fonte também destas mesmas mudanças portadoras de diversidades. (Zaoual, 2010, p .26).

De fato, o termo situação consistia numa das dez categorias filosóficas de Aristóteles e foi utilizado por filósofos contemporâneos para designar uma fase da experiência ou atividade determinada por um dado conjunto de condições concretas. O termo situação passa a ser utilizado por correntes filosóficas mais recentes para designar:

A relação total concreta do ser vivo, tal como ele é num momento dado, com o seu meio; em particular de um existente entre outros existentes. É nesse sentido que o termo passa a impregnar a expressão ser em situação utilizada para representar a posição do homem total, e não apenas da sua inteligência, diante de um problema de juízo ou de conduta que se the coloca (Lalande, 1999, pp.1036-1037).

De acordo com Mora (1964), a noção contemporânea de situação está intimamente ligada à filosofia da existência e à noção de realidade radical da vida, logo, uma situação é sempre total e vital. Ao apontar a necessária distinção entre termos que muitas vezes são considerados equivalentes (situação, circunstância e horizonte), a situação é remetida a uma realidade mais restrita e precisa, além de comportar outro ingrediente não circunstancial que é a aspiração de passar de uma situação para outra, como projeto e vontade.

Também Nicol (1996) assinala que viver é realizar propósitos e projetar-se no futuro através da ação. A situação não constitui apenas o que rodeia o sujeito, mas a relação vital que este mantém com o que lhe rodeia, logo, é um "dispositivo circunstancial formado por tudo que circunda o sujeito: a situação tem sempre e depende sempre de um prot-agonista, e esta agoné ou agonia, esta luta é exatamente o que constitui a vida do sujeito que está em situação" (idem, p.93). Somente o externo não constitui a situação, por isso a situação não se limita ao externo e por isso toda situação é vital: pois “os componentes subjetivo e 
transubjetivo, são em realidade indissolúveis e constituem uma unidade, a qual se expressa mediante o conceito funcional estar em que os articula [estar em situação]". (idem,p.107).

Sartre (1997) aponta o paradoxo no qual não há liberdade a não ser em situação, e não há situação a não ser pela liberdade. É somente na liberdade que o mundo desenvolve e revela as resistências que podem impedir a realização de algo projetado, realizações e obstáculos esses que só têm sentido e que apenas são iluminados em função de uma finalidade projetada. $\mathrm{O}$ autor elenca diferentes estruturas da situação que podem ser consideradas isoladamente, mas sem perder de vista o fundo sintético das demais com as quais constituem uma unidade absoluta: meu lugar; meu corpo; meu passado; meus arredores; e minha relação fundamental com o outro.

[...] é em relação ao que projeto fazer - em relação ao mundo em totalidade, e, portanto, a todo meu ser-no-mundo - que meu lugar aparece-me como um auxiliar ou um impedimento. Estar no lugar é, antes de tudo, estar longe de... ou perto de... - ou seja, o lugar está dotado de sentido em relação a certo ser ainda não existente que se quer alcançar. É a acessibilidade ou inacessibilidade deste fim que define meu lugar. [...] Por que, se o fim pode iluminar a situação, é pelo fato de ser constituído como modificação projetada desta situação (Sartre, 1997, pp. 606-607).

Para Sartre (1997) a situação constitui uma relação entre a condição e a liberdade, pois só se é livre em condição. Compreender a situação enquanto organização de um mundo significante à volta da livre escolha não é o mesmo que entendê-la como um determinado estado de coisas imposto. O presente, segundo esse autor, é iluminado pela livre invenção e pelo futuro. Os limites só adquirem tal sentido à luz dos fins de uma escolha de ação em função de um dado projeto, é pelo "posicionamento prévio de um fim, que surge o coeficiente da adversidade. Portanto, é nossa liberdade mesmo que deve constituir previamente a moldura, a técnica e os fins em relação aos quais as coisas irão manifestar-se como limites" (idem, p. 594).

Assim, podemos elencar pelo menos três traços filosóficos que interessam diretamente à geografia em sua interpretação dos nexos entre ação e espaço: (i) relação e reciprocidade (espacial); (ii) combinação de momentos (temporal); e (iii) condição ou disposição (adversa ou favorável) para a realização, no sentido de transcender um determinado estado de coisas em direção ao futuro (ação).

Todos esses traços e sentidos filosóficos de uma forma ou de outra iluminam, informam, animam ou são mantidos na proposta conceitual de situação geográfica. 


\section{SITUAÇÃO GEOGRÁFICA: RETOMANDO UM CONCEITO CLÁSSICO DA GEOGRAFIA}

De acordo com Brunet et al. (1993) a situação é a característica geográfica fundamental de um lugar ou de um espaço resultante de sua relação com outros lugares ou espaços. A análise da situação geográfica é vital para apreciar as qualidades de um lugar, pois todo lugar está situado em relação a outros lugares a partir de vias de comunicação e de vizinhança, sobretudo, situa-se em certas malhas e redes que determinam suas características e dinâmicas fundamentais.

Ao distinguir entre situação, sítio e posição, Claval (2011) assinala que a análise de situação é um tema clássico da geografia que se desenvolveu inicialmente em uma perspectiva naturalista muito próxima dos estudos do meio e com ênfase no papel das determinações do meio natural. Tal perspectiva que já estava presente na geografia antiga, ainda que de forma modesta, perdurará até a geografia da primeira metade do século XX. A análise clássica da situação sempre se caracterizou, prossegue o autor, pela polarização, ou seja, a análise parte de um ponto, de uma região ou de um país em relação ao qual tudo se vincula sistematicamente.

A análise da situação legou aos geógrafos a tarefa de compreender aquilo que observam a partir da consideração das diferentes escalas, ou seja, o entendimento de que algum aspecto local frequentemente se encontra em outras escalas, como a regional, a nacional ou a mundial. Uma primeira ruptura com a perspectiva da geografia antiga foi feita, segundo Claval (2011), por Carl Ritter ao associar a análise de situação com o conceito de totalidade, o que lhe permitiu vincular o particular ao todo, relacionando fenômenos em diversas escalas para compreendê-los.

Em obra de 1807, Ritter (1974) assinala a dimensão histórica como o elemento mais importante da disciplina geográfica, por isso o fator histórico constituiria o principal diferencial da geografia enquanto ciência, cuja principal tarefa seria aquela de estudar as relações globais a partir da observação dos espaços terrestres, da determinação de seus conteúdos e de suas relações com outras porções terrestres. O progresso técnico, sobretudo dos meios de circulação, modificou as relações e condições espaciais: "Semelhante evolução [das habilidades humanas] não poderia deixar de modificar completamente o valor da maioria dos espaços terrestres em suas situações relativas e nem de afetar suas posições" (Ritter, 1974, p. 140).

De fato, a compreensão de que ao sítio juntavam-se ações para explicar os dois termos marcou a geografia como disciplina histórica. 
Para Ritter (1974), o progresso da navegação oceânica modificou completamente a posição das terras, ilhas e continentes sobre a superfície terrestre. Assim, os impulsos naturais teriam exercido influência decisiva somente nos primeiros desenvolvimentos que "a humanidade em seu berço” conheceu: “... o homem ele-mesmo, vai se libertando progressivamente dos entraves que lhe são impostos pela natureza e sua morada: a Terra" (idem, p. 140).

Contudo, é a partir de Friedrich Ratzel e de Vidal de La Blache, na virada do século XIX para o XX, que o fenômeno da circulação, possibilitada pelo progresso técnico, se fará mais presente na análise da situação geográfica. Para esses autores o progresso técnico permite que os grupos humanos relativizem os condicionantes do meio físico local em que vivem.

Segundo Ratzel (1987), em obra de 1897, existem três grandes fatores político-geográficos que explicam os nexos entre um povo e seu espaço: (i) em primeiro e acima de tudo, a situação; (ii) a extensão; e (iii) as fronteiras. A situação geográfica seria uma constante do solo que permearia o movimento da história, um reservatório onde um povo pode se proteger e conserva-se a si mesmo como povo. Independentemente das influências do meio, a situação é o atributo de um lugar ou de um país em relação aos outros, definindo-se por uma multiplicidade de relações. Portanto, para o autor a análise geográfica da política supõe a consideração de dois parâmetros indissociáveis: de um lado a esfera política de ordem mais abstrata e, de outro, a situação que revela um caráter preciso, particular e orgânico existente em cada lugar.

La Blache (1921) também aponta que foi a circulação - de homens, ideias e mercadorias - que rompeu com um suposto determinismo do meio, pois ao permitir complementaridades, as relações de circulação de uma dada situação constituirão o centro das estratégias de adaptação dos grupos humanos. Cada situação varia segundo as técnicas de circulação, com os deslocamentos de homens, recursos e idéias.

Esses traços teóricos gerais - apresentados sumariamente - permanecerão presentes na geografia até os dias de hoje. Temporalmente o conceito é, de certa maneira, deixado em segundo plano depois das publicações de Vidal de La Blache nos anos 1920, para ser retomado por Pierre George somente nos anos 1960 e, a partir de então, ganhou influência explicativa, especialmente depois dos anos 1980, quando então a globalização passa a ser um fenômeno em que a multiplicação da circulação se generaliza em escala planetária, solicitando assim novas interpretações quanto à posição dos lugares nas dinâmicas do espaço. 
A proposta teórica de Pierre George (1969) é um divisor de águas entre as interpretações de um mundo menos veloz, onde a fluidez dos territórios ainda estava em seus balbucios, e o mundo em que a vertigem da velocidade levou à avaliação, apressada, de que o tempo estaria anulando o espaço e, portanto, as situações resultariam apenas e tão somente da história, sem nenhum papel ativo do espaço sobre os grupos sociais. George (1969) define situação geográfica como um tipo de correlação de forças analisada a partir do balanço do conjunto de forças e ações que podem ser concorrentes, competitivas, contraditórias ou complementares. Assim, situações podem ser definidas como correlações de forças que englobam tendências evolutivas, pois a análise de situação percebe os fatos no momento em que a situação permanece aberta. Esse autor sugere as seguintes variáveis cujas combinações únicas sintetizam situações geográficas: (i) relações entre a vida econômica e social; (ii) presença de recursos naturais; (iii) densidade e estrutura etária da população; (iv) condições jurídicas; (v) dimensões quantitativa e qualitativa da produtividade, do capital e do trabalho (densidade econômica); (vi) balanços migratórios. (vii) esquema das vias de circulação e transportes; e (viii) rede urbana.

O presente texto não pretende ser um manual, tampouco tem condições de esgotar o complexo enredo teórico que envolve extensa produção bibliográfica e suas interpretações; contudo, nosso intuito é aquele de circunscrever um campo dentro do qual - e o explicitamos - nos movemos teoricamente, para dele extrair, dentre múltiplas possibilidades, uma síntese - sempre provisória - sobre a racionalidade que preside cada uma das interpretações dos autores. De fato, desde Ritter, Ratzel e La Blache, o que avulta na literatura (Cole, 1978; Durand et al., 1993; Albuquerque, 2006; Damiani, 2010) é a ideia de movimento, de circulação para além dos quadros locais e regionais. Destaca-se, especialmente, a ideia de que o lugar é uma escala abalada pelos fluxos - de ideias, mercadorias e pessoas - que o perpassam.

Tradicionalmente essa literatura epistemológica apresenta a situação geográfica como as relações internas a um sítio, mais as ações que se davam sobre ele, contudo, hoje as relações locais são muito mais complexas, porque sobre o sítio não incidem apenas vetores locais, mas também interesses exógenos nacionais e, muitas vezes também globais, mudando, portanto, a situação dos lugares e sua relação com o mundo. Nesta aceleração contemporânea parte substancial do edifício local, das horizontalidades, deriva das verticalidades da globalização hegemônica (Santos, 1999a). A diferenciação entre os lugares vem do fato deles serem diversamente alcançados, qualitativa e quantitativamente, por elementos móveis que agem em conjunto "para definir uma situação geográfica, reforçando-se ou contrariando-se uns aos outros" (George, 1969, p. 14). 
Silveira (1999) define situação geográfica como um conjunto de forças e eventos que ao se geografizarem mudam a situação dos lugares e sua relação com o mundo. Ao se geografizarem os vetores reordenam as materialidades e condicionam nos lugares novas possibilidades, mudando, assim, o campo de ação. A autora propõe que a situação seja analisada sob três perspectivas indissociáveis: (i) as estruturas históricas herdadas; (ii) a conjuntura e a coerência dos eventos presentes nos lugares; e (iii) a âncora no futuro, ou projeto dos lugares lançado pela situação geográfica. Assim, todos os vetores que os lugares acolhem formam situações novas que redirecionam a flecha do tempo em direção a novos futuros possíveis.

Especialmente neste período em que os lugares têm suas autonomias relativizadas, o uso do conceito de situação geográfica representa um caminho de método seguro para as análises dos lugares e das configurações regionais. Uma situação geográfica é um complexo de forças em ação presente, organizada segundo feixes de variáveis que se juntam numa combinação única e inédita num dado momento e num dado subespaço. Ela resulta da interação de variáveis que, precipitadas no lugar, se tornam interdependentes. Quando mudam as combinações entre as variáveis, ao sabor de eventos nacionais ou globais, que escapam ao controle do lugar, surgem situações geográficas inéditas que redefinem a vida de relações local. Para George (1969, p. 14), a geografia está destinada "a realizar balanços de ações concorrentes e, muitas vezes, competitivas ou contraditórias, outras vezes, também complementares. /.../ A geografia tem por objeto definir situações complexas /.../ Isto confere à geografia o caráter de pesquisa de informação para a ação política”.

Se, por um lado, incidem nos lugares vetores externos (as verticalidades) que buscam impor uma racionalidade dominante de caráter mais organizacional - para a qual o território importa mais como recurso - por outro lado, os lugares abrigam uma força emanada de horizontalidades fundadas na vizinhança, no cotidiano compartido, nas temporalidades e racionalidades diversas, uma heterogeneidade criadora cujas solidariedades tanto obrigadas quanto desejadas são produtoras de futuros possíveis - no sentido de possibilidades de existência - e para as quais o território é, sobretudo, abrigo (Santos, 1999a). Não se trata de um dualismo entre verticalidades e horizontalidades, mas de um recorte analítico para compreensão de uma totalidade em processo de totalização.

Para compreender o processo cada vez mais intenso e acelerado de diferenciação regional e de compartimentação política do mundo, Gottmann (2007) assinalou a importância das dimensões psicológica e cultural e não apenas dos condicionantes materiais. Nesse processo de diferenciação o autor sublinha uma dialética entre a iconografia regional e a circulação, ou seja, entre sistemas de resistência e sistemas de movimento. Uma contradi- 
ção entre forças de circulação, universalismo e unificação, de um lado, e forças de iconografia, compartimentação e diversidade, de outro.

O movimento de circulação é toda força de criação e de mudança na ordem estabelecida em um lugar, consistindo em movimentos e deslocamentos de toda ordem. Força transportadora de contatos, homens, ideias, objetos e técnicas que dinamiza sistemas de relações. Recorte analítico fundamental, que tal como o conceito de verticalidade, permite compreender a interdependência e os nexos entre os distintos lugares e pontos do mundo. Já os sistemas de resistência ao movimento são de ordem material e também imaterial e abstrata, uma solidariedade criada a partir da co-habitação num mesmo espaço. A iconografia exerce, assim, uma ação limitadora à circulação, uma resistência, que é um fator de estabilização política (Gottmann, 2007, p. 221).

No atual período, quando se aceita, sem resistências e desvios, a sistematização do mundo orientada pela "ótica mercantil ilimitada e pelo acionamento de estratégias econômico-militares que transformam contextos da vida coletiva em alvos de investimentos sem compromissos com a preservação de heranças culturais, acúmulos institucionais e conquistas coletivas" (Ribeiro; Silva, 2013, p.141), o movimento de circulação passa a ser lido como impulso global, como movimento de subordinação e tendência à ação irrefleti$d a$, "indicando a falta de controle da ação pela vontade" (idem, p. 151) e o "deslocamento da ação das condições herdadas" (idem, p. 152).

Assim, com base no conceito de situação geográfica, buscamos analisar as políticas e programas de fitoterapia no Sistema Único de Saúde (SUS) das regiões brasileiras (Ribeiro, 2015). De fato, o território nacional é uma espécie de caleidoscópio diferentemente desenhado ao longo do tempo e permanentemente reconfigurado pelos diferentes impactos das ações e eventos em cada lugar. Logo, a implantação seletiva de políticas e programas do SUS no território nacional atribui distintos valores às suas diversas frações, ao mesmo tempo em que são alteradas as relações entre as regiões. Incorporando as ideias de sítio, de ação e de vetores externos que incidem sobre o sítio e as ações locais, o conceito de situação geográfica permite uma abordagem operacional da escala do lugar e da região.

Nesse sentido, cabe identificar, periodizar e hierarquizar os elementos fundamentais presentes numa situação e, a partir deles, desvendar o complexo de relações da situação. 


\section{A POLÍTICA DE PLANTAS MEDICINAIS E FITOTERÁPICOS NO SISTEMA ÚNICO DE SAÚDE (SUS): OITO SITUAÇÕES GEOGRÁFICAS}

Em 2006 o Ministério da Saúde instituiu a Política Nacional de Plantas Medicinais e Fitoterápicos (PNPMF) e, em 2008, o Programa Nacional de Plantas Medicinais e Fitoterápicos e seu Comitê Gestor (composto por representantes do Estado, da sociedade civil organizada, de movimentos sociais e das universidades). Embora não tenha sido a primeira iniciativa contemporânea do governo federal ${ }^{1}$, a política nacional possuía dois objetivos claros. Em primeiro lugar atender às demandas de experiências e programas municipais de fitoterapia no serviço público de saúde, tanto as existentes como as projetadas, e em segundo lugar responder às orientações internacionais e nacionais de fomento e valorização da adoção de plantas medicinais e fitoterápicos decorrentes de eventos globais.

Quanto ao primeiro objetivo, assinala-se a existência de programas municipais de fitoterapia na saúde pública desde meados dos anos 1980, animados em parte pelos eventos globais, seja de modo mais independente e local, seja como resultado do PPPM/CE$\mathrm{ME}$, portanto, como densidades mais sedimentadas e horizontalizadas das primeiras vagas da atual modernização da fitoterapia. Mas também algumas experiências de usos de plantas medicinais e fitoterápicos na saúde pública, tanto em programas municipais como em unidades ou equipes do sistema público local, que resultavam - e muitos ainda hoje resultam - do diálogo e incorporação das heranças dos lugares e dos usos populares de saúde com base em plantas medicinais e fitoterápicos. Toda essa gama de utilizações da fitoterapia na saúde pública constitui um campo de força que atua há algum tempo como demandante de políticas e programas nacionais de apoio e fomento à incorporação de plantas medicinais e fitoterápicos no SUS.

Destacam-se dois importantes eventos globais que dinamizaram os usos de plantas medicinais e fitoterápicos sob novas bases: o movimento de contracultura dos anos 1960, cujo grande ícone foi representado pelo movimento de Maio de 1968 na França; e a Conferência Internacional sobre Assistência Primária em Saúde realizada em Alma-Ata no Cazaquistão, em 1978, pela Organização Mundial da Saúde da Organização das Nações Unidas (OMS/ONU).

O movimento de contracultura ao contestar a autoridade e a hierarquia, dentre elas a médica e a científica, promoveu novos comportamentos e hábitos, dentre os quais uma vida mais saudável e natural baseada em dietas alimentares e uso de plantas medicinais.

\footnotetext{
Destacando-se o Programa de Pesquisa de Plantas Medicinais (PPPM) da Central de Medicamentos (CEME), que vigorou entre 1982 e 1997, mas que de fato funcionou apenas nos anos 1980. Do PPPM/CEME resultou boa parte dos programas pioneiros de fitoterapia na saúde pública nos anos 1980, sendo que alguns criados nos 1990, já no contexto do SUS, também são tributários das ações desenvolvidas por esse primeiro programa nacional.
} 
Um dos muitos desdobramentos desse movimento internacional foi o surgimento do movimento ambientalista ou ecologista (cuja referência foi a Primeira Conferência Mundial sobre o Homem e o Meio Ambiente, a Conferência de Estocolmo de 1972), no bojo do qual também ocorre uma valorização das plantas medicinais e fitoterápicos.

Já do segundo evento surgiu a Declaração de Alma-Ata de 1978, que ao fomentar a autonomia e autodeterminação das sociedades e países na escolha dos sistemas médicos e de tratamento nacionais, estimulou a adoção das chamadas práticas de Medicina Tradicional e Medicina Complementar e Alternativa (MT/MCA), dentre as quais a fitoterapia ${ }^{2}$.

Ambos os eventos globais terão maiores repercussões no Brasil a partir dos anos 1980, período no qual o país buscava a redemocratização e nesse contexto será aprovada a criação, com a Constituição de 1988, do SUS. Nele serão valorizados os usos de plantas medicinais e fitoterápicos a partir de novas bases animadas pelos eventos globais. Essas proposições serão acolhidas por um país com forte herança, diversidade e presença cultural de práticas com plantas medicinais e fitoterápicos. Inclusive, são registradas experiências de programas municipais de fitoterapia na saúde pública em meados dos anos 1980 - anteriores à própria criação do SUS em 1988 - animadas tanto pelos vetores mundiais quanto pelas práticas e forças populares dos lugares.

$\mathrm{Na}$ análise realizada de situações geográficas que condicionam e são condicionadas pelos programas de fitoterapia no SUS, identificamos diferentes combinações entre circulação e impulsos globais na valorização da fitoterapia (verticalidades) e forças das iconografias regionais de usos populares (horizontalidades). Uma situação geográfica enquanto nó de verticalidades e horizontalidades é, assim, uma síntese provisória da dialética entre forças iconográficas e forças de circulação, entre pulsações e impulsos globais. O sítio enquanto iconografia, território usado e herdado, impregna a sociedade sem determinar completamente seus comportamentos, um modelador modelado, uma materialidade animada pela ação, pelo território sendo praticado. A situação é uma síntese sempre provisória, inconclusa e aberta.

A análise sobre os condicionantes territoriais dos programas de fitoterapia do SUS visitados durante a pesquisa ${ }^{3}$ - permitiu identificar situações geográficas distintas em cada

\footnotetext{
2 Após duas décadas e meia de recomendações, documentos, experiências e ações de práticas alternativas de saúde e de programas de fitoterapia no sistema público de saúde no Brasil ocorrerá a criação pelo Ministério da Saúde da Política Nacional de Práticas Integrativas e Complementares em Saúde e da Política Nacional de Plantas Medicinais e Fitoterápicos, ambas em 2006.

3 Foram realizadas 81 entrevistas nos dez trabalhos de campo, entre novembro de 2010 a janeiro de 2014, em oito estados brasileiros (Paraná, São Paulo, Minas Gerais, Goiás, Mato Grosso, Pernambuco, Ceará e Pará) mais o Distrito Federal, abarcando 24 municípios e três regiões administrativas do Distrito Federal (Plano Piloto, Planaltina e Riacho Fundo), contemplando-se 14 programas de fitoterapia no SUS (Ribeiro, 2015).
} 
uma das macrorregiões ${ }^{4}$ escolhidas. $\mathrm{O}$ conjunto de dados primários e secundários foi sistematizado consoante oito variáveis: (i) população; (ii) normas; (iii) estratégias de produção dos programas; (iv) grau de dependência do mercado; (v) agentes estatais e não estatais; (vi) grau de integração com saberes e práticas locais; (vii) constrangimentos e fatores limitantes aos programas de fitoterapia no SUS; e (viii) perspectivas e planos futuros para os programas.

Todas essas oito variáveis foram analisadas individualmente e depois colocadas em um conjunto de relações recíprocas, já que essas variáveis se articulam em sistema. Embora observáveis em todas as situações analisadas e identificadas, a combinação sistêmica das oito variáveis é única em cada caso, em virtude de ser cada combinação, ao mesmo tempo, produto e produtora de uma dada situação geográfica.

A partir desse esforço teórico-empírico chegamos a um conjunto de oito situações geográficas identificadas nas quatro macrorregiões brasileiras, quais sejam:

Na Região Concentrada: situação geográfica de área core (São Paulo-SP e Campinas-SP); situação de iconografia campesina (municípios do oeste do estado do Paraná: Foz do Iguaçu, Toledo, Medianeira, Pato Bragado e Vera Cruz do Oeste); e situação geográfica intermediária entre área core e iconografia popular (Betim-MG);

Na Região Centro-Oeste: situação geográfica de impulsos globais (Riacho Fundo-DF; Goiânia-GO); e situação geográfica de iconografia popular (Cuiabá-MT; Planaltina-DF; e Diorama, Arenópolis, Aragarças, Jussara e Iporá no estado de Goiás);

Na Região Nordeste: situação geográfica de iconografia popular de brenhas (Recife, Olinda, Jaboatão dos Guararapes e Brejo da Madre de Deus no estado de Pernambuco; e Fortaleza e Maracanaú no estado do Ceará);

E na Região Amazônica: situações geográficas de impulsos globais e de iconografia popular (município de Belém no estado do Pará).

Na Região Concentrada são destacadas as densidades técnica, científica e informacional presentes no eixo São Paulo/Campinas (SP), que autorizam um espaço especialmente fluído para responder aos ditames da centralização dos capitais, por isso interpretá-lo como área core dessa macrorregião.

A Região Concentrada, abrangendo São Paulo, Rio de Janeiro, Minas Gerais, Espírito Santo, Paraná, Santa Catarina e Rio Grande do Sul, caracteriza-se pela implantação mais consolidada dos dados da ciência, da técnica e da informação. [...] Nessa Região Concentrada

\footnotetext{
4 Partimos das quatro macrorregiões ou os quatro brasis - Região Concentrada, Região Centro-Oeste, Região Nordeste e Região Amazônica - propostos por Santos e Silveira (2001). Fundamental para nós é o quadro teórico-conceitual em que se baseia essa regionalização que é a difusão diferencial do meio técnico-científico-informacional sobre as heranças regionais do território brasileiro no período da globalização.
} 
do país, o meio técnico-científico-informacional se implantou sobre um meio mecanizado, portador de um denso sistema de relações, devido, em parte, a uma urbanização importante, ao padrão de consumo das empresas e das famílias, a uma vida comercial mais intensa. Em conseqüência, a distribuição da população e do trabalho em numerosos núcleos importantes é outro traço regional. [...] o Sudeste, mais "novo" que o Nordeste e mais "velho" que o Centro-Oeste, consegue, a partir do primeiro momento de mecanização do território, uma adaptação progressiva e eficiente para os interesses do capital dominante. Cada vez que há uma modernização, esta é encampada pela região (Santos e Silveira, 2001, pp.269-275).

É no estado de São Paulo onde são identificadas manchas mais contínuas do meio técnico-científico-informacional e, por isso, onde é mais intensa a concentração das variáveis que propiciam a adoção da fitoterapia no SUS. São Paulo é o Estado onde mais são instituídos programas municipais de fitoterapia no SUS e, ao mesmo tempo, onde é maior o índice de descontinuidade, interrupção e mortalidade dos programas.

A situação geográfica de área core apresenta uma intensidade maior dos impulsos globais e das forças de circulação, reverberando e gerando impulsos para as demais regiões do país. A situação geográfica de área core é a expressão da força de inércia e de atualização constante da biomedicina, cujos componentes e agentes exercem a hegemonia no sistema de saúde brasileiro ${ }^{5}$. A biomedicina é aqui compreendida não como sinônimo de medicina científica moderna, mas como a associação estreita entre a prática em saúde - fundada na racionalidade da medicina técnico-científica moderna e dirigida pela classe médica -, o capital monopolista baseado na indústria da saúde (de medicamentos, de equipamentos e dos serviços prestadores e laboratoriais) e o Estado.

A presença cerrada desses componentes da biomedicina torna mais difícil a integração e duração dos programas de fitoterapia, pois os componentes desse subsistema não são hegemônicos e, muitas vezes, são contra-hegemônicos porque fundados em outras racionalidades e contextos mais amplos, heterogêneos e plurais dos agentes envolvidos. Se por um lado a concentração de variáveis do período favorece a adoção da fitoterapia no SUS, por outro, a incidência acirrada das forças de circulação e dos impulsos globais parecem tornar difícil a duração, sobrevivência e integridade dos programas.

\footnotetext{
Dentre seus atributos, destacam-se: (i) a lógica médica da biomedicina permeando as atividades dos profissionais de saúde, tanto na formação e pesquisa como na rotina de trabalho desses profissionais, principalmente médicos; (ii) a concepção da saúde como bem econômico e individual, muito vinculada também à ideia de saúde como sinônimo de assistência médica, que é apenas um dos componentes do sistema de saúde; (iii) a força e pressão da atuação da indústria da saúde (de equipamentos, de medicamentos e de serviços) junto às universidades e centros de formação e pesquisa, aos profissionais da área (em particular dos médicos), das unidades e serviços de saúde (públicos e privados), dos gestores públicos e da população de um modo geral através da difusão de uma psicoesfera, com destaque para a publicidade e para promoção de medicamentos tanto em pontos de venda (drogarias, farmácias e outros pontos comerciais) como em consultórios, demais estabelecimentos de saúde e até mesmo escolas; e (iv) a incorporação pela gestão e administração públicas, tanto da saúde como das outras áreas, do ideário da gerência científica e de critérios administrativos do mercado, corroborando para a despolitização e para a amplificação do estado presente das coisas.
} 
Na porção mais ao sul da Região Concentrada, também identificamos uma situação geográfica de iconografia popular campesina. Ainda que o componente mais recente da modernização da fitoterapia fundada no ideário ambientalista se faça presente, predomina a variável de identidade cultural com a terra e com as tradições de cuidados familiares com a utilização de plantas medicinais, com forte presença dos movimentos campesinos, pastorais da igreja e comunidades eclesiais de base. As pastorais da igreja e as comunidades eclesiais de base estão presentes em todas as macrorregiões brasileiras, constituindo importantes agentes nos usos populares da fitoterapia.

A situação geográfica de iconografia popular campesina funde um conjunto de atributos que podem ser assim elencados: (i) o uso de plantas medicinais como tradição familiar e comunitária fortemente enraizada, identificado como importante componente da identidade cultural ligada à questão da terra; (ii) dada a intensa migração de origem europeia no povoamento da região, boa parte das plantas medicinais utilizadas constituem-se de espécies já globalizadas há mais tempo e, por isso, com maior volume de estudos e pesquisas, além de produção econômica para mercados, o que faz com que atendam aos critérios de ciência, informação e norma, facilitando sua adoção nos programas de fitoterapia; e (iii) a presença de movimentos sociais campesinos, sindicatos e associações de trabalhadores da agricultura, cooperativas agrícolas e pastorais da igreja, que desempenham importante papel na primeira etapa produtiva dos programas que é a do cultivo de plantas medicinais, além de fortalecerem os vínculos populares dos programas com as heranças e as práticas e saberes locais.

Ainda na Região Concentrada, destacam-se também situações geográficas intermediárias que permanecem, de modo geral, mais circunscritas a agentes sediados em um mesmo município. Ainda que não existam situações geográficas autárquicas - pela própria definição do conceito - reconhecemos alguns programas municipais que permanecem, de certa maneira, não integrados a outros programas em uma mesma área de proximidade. Distintamente, na situação iconográfica campesina a solidariedade entre agentes sediados em municípios distintos é mais intensa e preponderante, sendo maior a circulação de informações entre os agentes e mais abrangente a área de atuação.

O componente cultural que predomina nessa situação intermediária está mais associado a movimentos de caráter urbano, como a situação de área core, a partir de modernizações desdobradas dos eventos globais recentes. A adoção da fitoterapia no SUS que produz e é produzida por essa situação é expressão de modernizações impulsionadas pelos eventos do movimento ambientalista e das Práticas Integrativas e Complementares em saúde, cujas ações têm sido conduzidas, principalmente, por profissionais da saúde (desta- 
cando-se médicos e farmacêuticos) em articulação com profissionais de outras áreas (botânicos e agrônomos vinculados às práticas da agroecologia e da permacultura).

Já na Região Centro-Oeste foram identificadas duas situações geográficas, de impulsos globais e de iconografia popular. Em ambas há dificuldade de enraizamento e perenidade dos programas de fitoterapia, sobretudo, considerando o acentuado descompasso nessa macrorregião entre o sistema técnico estatal e o território usado por uma diversidade de agentes cuja pluralidade enfrenta muita resistência para se expressar nas políticas ${ }^{6}$. Assim, predominam situações de impulsos globais caracterizadas por forças de movimento e circulação com acentuada dificuldade de integração com a diversidade de usos populares de plantas medicinais e fitoterápicos constituintes das forças iconográficas da macrorregião.

Os programas de fitoterapia dessas situações são caracterizados por elementos e ideários desdobrados dos impulsos globais do movimento de contracultura dos anos 1960 acolhidos pela Região Centro-Oeste, como: o movimento ambientalista e ecologista; o orientalismo e misticismo; e as práticas tradicionais e alternativas de saúde traduzidas nas Práticas Integrativas e Complementares em Saúde. A despeito das forças de circulação e dos obstáculos à formação de vínculos fortes e perenes dos programas de fitoterapia no SUS junto às práticas e agentes enraizados no lugar, a permanência e força das estratégias estudadas na Região Centro-Oeste reforçam e são tributárias da situação geográfica de iconografia popular, expressão dos usos do território por populações que historicamente têm ocupado a região, uma diversidade que usa o território como abrigo.

As modernizações, por sua própria dialética, são portadoras de forças contraditórias, dentre as quais existem aquelas cujo ideário político e cultural é mais aberto e permeável à pluralidade dos agentes. As sucessivas ondas migratórias também decantaram uma cultura de organização política contra-hegemônica nessa macrorregião, expressa em ações de médicos sanitaristas e profissionais vinculados à saúde coletiva, farmacêuticos comprometidos com o conhecimento e as práticas populares, técnicos, agrônomos e agricultores atualizando ideário e práticas de organização política trazidos de outros lugares (Movimento Mutirão; Movimento Guaranítico; Movimento Encruzilhada Natalino), movimentos sociais (como o Movimento dos Trabalhadores Sem Terra - MST, Articulação Nacional de Agroecologia e associações regionais de produtores), a presença antiga e capilarizada de farmacinhas populares e farmacinhas comunitárias vinculadas a pastorais da igreja, associações comunitárias, de agricultores familiares e de grupo de mulheres ainda muito presentes nessa região.

\footnotetext{
6 Verificamos que esse é um dado da formação socioespacial brasileira, identificado nos trabalhos de campo realizados nos programas de fitoterapia no SUS das demais macrorregiões do país, mas que se sobressaiu na Região Centro-Oeste e, principalmente, na Região Amazônica.
} 
Já na Região Nordeste, mais do que em qualquer outra macrorregião brasileira, a densidade iconográfica popular exerce forte influência nos programas de fitoterapia no SUS. A difusão do meio técnico-científico-informacional através da fitoterapia no SUS tem se caracterizado por uma acentuada integração com os saberes e práticas populares através dos vínculos entre variáveis do período (técnica, ciência e informação) e a densidade iconográfica e suas solidariedades orgânicas. Os trabalhos de campo realizados sugerem que uma variável de caráter mais comunicacional tem propiciado esse vínculo pelo qual usos populares têm informado a política do SUS. Atestando a força e presença da situação geográfica de iconografia de brenhas, de um passado que se faz presente, e que tem se atualizado através dos programas de fitoterapia no SUS, constituindo uma marcante contrafinalidade à rigidez da racionalidade e à hegemonia da biomedicina que presidem o sistema de saúde brasileiro.

A situação geográfica de iconografia popular de brenhas é constituída por forte conteúdo cultural de identidade popular e regionalista, por círculos de cooperação e comunicação extensos e difusos, entre agentes estatais e não estatais sediados em municípios de distintas regiões e estados e, de modo geral, os programas conseguem estabelecer fortes vínculos com as heranças (institucionais e culturais) e com práticas e saberes populares e tradicionais, marcados por uma acentuada tendência de integração com as solidariedades orgânicas dos lugares e uma insistência dos agentes para que assim seja.

Na Região Amazônica, os programas de fitoterapia no SUS são fortemente condicionados por situações geográficas de impulsos globais. O que reforça, por sua vez, as forças de movimento e circulação que incidem de forma pontual nessa macrorregião caracterizada por uma vastidão de situações geográficas de iconografia popular extremamente diferenciadas que, no caso do subsistema de fitoterapia no SUS, se tornam invisíveis e silenciadas. Foram identificadas duas estratégias distintas de ações sob a perspectiva dos programas de fitoterapia no SUS. Uma situação geográfica de ordem mais horizontal, ou seja, uma iconografia mais silenciosa e não vista, e outra impulsionada mais verticalmente, evidenciando certa incapacidade e limitação do sistema de saúde em lidar com a diversidade brasileira.

Na Região Amazônica, embora haja presença fundamental de grupos indígenas, ribeirinhos, seringueiros, caboclos, quilombolas e toda diversidade de populações que vivem historicamente dos usos da floresta, identificamos dificuldades no estabelecimento de vínculos entre os programas de fitoterapia no SUS e os usos populares de plantas medicinais, ainda que estes usos sejam muito visíveis e presentes no cotidiano das culturas amazônidas. 
Foram identificadas duas situações geográficas na Região Amazônica: (i) situações marcadas pelas experiências de uso de plantas medicinais mais espontâneas no sistema público de saúde, que não se institucionalizam como programas e que são sub-notificadas e não informadas, pelas mais diversas razões (escassez informacional do lugar; escassez comunicacional do sistema; ou mesmo por ser uma estratégia dos gestores e agentes de saúde desses lugares para não se exporem); e (ii) situações de impulsos globais com dificuldade de integrar os usos populares de plantas medicinais aos programas de fitoterapia institucionalizados, que são justamente aqueles informados e notificados e que, por isso, aparecem nos registros oficiais como os representantes das práticas de fitoterapia no sistema.

Mais do que em qualquer outra macrorregião brasileira visitada, na Amazônica os programas de fitoterapia no SUS têm grande dificuldade de integrar os usos populares de plantas medicinais e fitoterápicos ao sistema, e quando o fazem ou são marcados pela subnotificação e invisibilidade para o sistema (quando em certa medida a iconografia tende a informar a política num movimento de baixo para cima, através das práticas de agentes e equipes do sistema público de saúde) ou reforçam uma situação geográfica de impulsos globais de cunho corporativo que fragmenta o território e não estabelece vínculos mais orgânicos com as iconografias do lugar.

\section{CONSIDERAÇÕES FINAIS}

Não pretendemos propor ou erigir alguma forma de manual ou modelo, tampouco alguma espécie de manual de ação ou planejamento. Apresentamos uma pesquisa empírica e uma revisão bibliográfica do conceito de situação geográfica de forma sistematizada buscando assinalar e demarcar os principais traços desse conceito clássico da geografia e sua pertinência teórico-metodológica, demonstrada com um breve panorama de pesquisa realizada, na qual foram identificadas algumas situações geográficas em diversas regiões do Brasil.

Nosso desafio foi valorizar e avançar na análise das situações geográficas a partir da compreensão do espaço geográfico como um sistema indissociável - um híbrido - de sistemas de objetos e sistemas de ações. Entendemos que desse par analítico, o sistema de objetos é histórica e habitualmente muito mais abordado e descrito, ele é mais frio, enquanto que no caso do sistema de ações, muitas vezes observamos maiores limitações e dificuldades na abordagem, talvez por ser mais quente, ou seja, por ser um sistema em que as ações informam aos objetos novas funções em um tempo muito mais presto que as transformações nos sistemas de objetos. 
O conceito de situação geográfica foi privilegiado no estudo dos programas de fitoterapia no SUS em virtude da articulação que ele promove entre elementos analíticos estruturais e conjunturais, permitindo avaliar os programas de fitoterapia como ações políticas que, embora conjunturais, não estão descoladas de uma estrutura que as valoriza ou as deprime, já que a estrutura é referida às interrelações das partes de um todo, ou seja, o modo de organização ou construção da totalidade social. Ambas - estrutura e conjuntura - se articulam e são analiticamente compreendidas como momento do processo da totalidade em movimento, ou seja, da totalização, da dialética entre sítio e ação. As situações geográficas permitem compreender a tensão permanente entre as estratégias dos agentes e os condicionantes territoriais, porque as conjunturas reforçam ou destroem estruturas, e estas limitam ou permitem certas manifestações conjunturais. Como afirma Ribeiro (2002), todo o tempo a ambição é intervir na conjuntura para produzir alterações estruturais, ou seja, transformações na organização da sociedade e do espaço. Eis a vontade maior: compreender para modificar!

Ao valorizar as ações, estratégias e táticas dos agentes, o conceito de situação geográfica revela-se fundamental no esforço das análises conjunturais aliada à compreensão das estruturas históricas. Além de sua pertinência como marco teórico-metodológico que permite compreender o período atual - no qual a velocidade é uma de suas variáveis-chave também autoriza uma mais justa interpretação da diferenciação entre os lugares - dentro do contexto do período atual. Assim fazendo, estamos buscando o velho paradigma em geografia, aliar o tempo aos estudos do espaço.

\section{BIBLIOGRAFIA}

1. ALBUQUERQUE, Mariana Vercesi de. Território usado e saúde: respostas do Sistema Único de Saúde à situação de metropolização em Campinas - SP. Dissertação (Mestrado). Faculdade de Filosofia, Letras e Ciências Humanas da Universidade de São Paulo. São Paulo, 2006.

2. AUAT, Alejandro. Hacia uma filosofia política situada. Buenos Aires: Waldhuter Editores, $1^{\text {a }}$ Ed., 2011, 240 p.

3. BRUNET, Roger; FERRAS, Robert; THÉRY, Hervé. (1992). Les mots de la géographie, dictionnaire critique. Montpellier-Paris: Reclus - La Documentation Française, 3a Ed., 1993. 520 p.

4. CLAVAL, Paul. (2001). Epistemologia da geografia. Florianópolis: Editora da UFSC, 2011.

5. COLE, John Peter. (1975). Situations in human geography: a practical approach. Oxford: BasilBlackwell, 1978, (c1975), 238 p. 
6. DAMIANI, Amélia Luisa. Urbanização crítica e situação geográfica a partir da metrópole de São Paulo. In: CARLOS, Ana Fani Alessandri; OLIVEIRA, Ariovaldo Umbelino (org.), Geografias de São Paulo: representação e crise da metrópole. São Paulo: Contexto, $1^{\text {a }}$ edição, 2010, pp. 19-58.

7. DURAND, Marie-Françoise; LÉVY, Jacques; RETAILLÉ, Denis. Le monde: espaces et systèmes. Paris: Presses de La Fondation Nationale dês Sciences Politiques \& Dalloz, $12^{\mathrm{a}}$ edição, 1993. $597 \mathrm{p}$.

8. GEORGE, Pierre. Sociologia e Geografia. (1966). Rio de Janeiro / São Paulo: Companhia Editora Forense, 1969.

9. GOTTMANN, Jean. (1952). La politique des États et leur géographie. Paris: Éditions Du CTHS, 2007. 264 p.

10. JAPIASSU, Hilton; MARCONDES, Danilo. Dicionário básico de filosofia. Rio de Janeiro: Jorge Zahar Editor, 2001.

11. KAHIL, Samira Peduti. Psicoesfera: uso corporativo da esfera técnica do território e o novo espírito do capitalismo. Sociedade \& Natureza (UFU. Impresso), v. 22, p. 22-35, 2010.

12. LA BLACHE, Vidal de. Principes de Géographie Humaine. Publies d’apres lês manuscrits de l'auteur par Emmanuel de Martonne. Paris: A. Colin, 1921.

13. LALANDE, André. Vocabulário técnico e crítico da filosofia. São Paulo / SP: Martins Fontes, $3^{\text {a }}$ edição, 1999.

14. LÉVY, Jean-Pierre. Les situations locales de l'habitat: une method d'analyse. L'Espace Geographique, Tome XXI, n.1, 1992, pp. 5-14.

15. MERRIFIELD, Andy. Situated knowledge through exploration: reflections on Bunge's "geographical expeditions". Antipode, 27:1, 1995, pp.49-70.

16. MORA, José Ferrater. Diccionario de Filosofía. Montecasino, Editorial Sudamericana Buenos Aires, $5^{a}$ edición, 1964.

17. NICOL, Eduardo. (1941). Psicologia de las situaciones vitales. México DF: Fondo de Cultura Economica, 1996, $166 \mathrm{p}$.

18. RATZEL, Friedrich. (1897). La Géographie Politique - Les concepts fondamentaux. Librairie Arthème Fayard, 1987.

19. RIBEIRO, Ana Clara Torres. Pequena Reflexão sobre Categorias da Teoria Crítica do Espaço: Território Usado, Território Praticado. Em: Território Brasileiro - Usos e Abusos. Organizadora Maria Adélia Aparecida de Souza [et al..]. Campinas: Edições Territorial, 2003, pp. 29-40.

20. RIBEIRO, Ana Clara Torres. Teorias da Ação. Apostila com transcrição do Curso Teorias da Ação ministrado na Universidade Estadual de Campinas. Campinas, SP: Unicamp, 18 a 22 de novembro de 2002, $264 \mathrm{p}$.

21. RIBEIRO, Ana Clara Torres; SILVA, Cátia Antonia da. Impulsos globais e espaço urbano: sobre o novo economicismo. Em: RIBEIRO, A. C. T. Por uma sociologia do presente: ação, técnica e espaço - Vol. 5. Rio de Janeiro: Letra Capital, 2013, pp.139-170. 
22. RIBEIRO, Luis H. L. Território e macrossistema de saúde: os programas de fitoterapia no Sistema Único de Saúde (SUS). Tese (Doutorado). Instituto de Geociências da Universidade Estadual de Campinas. Campinas-SP: 2015, 322 p.

23. RITTER, Carl. (1807). Introduction à la géographie general e comparée. Annales Littéraires de L’Université de Besançon, 155, Les Belles-Lettres, 95, Boulevard Rapail, Paris Vie, 1974.

24. SANTOS, Milton, (1996). A natureza do espaço: técnica e tempo - razão e emoção. São Paulo: Hucitec, $3^{\text {a } e d i c ̧ a ̃ o, ~ 1999 a . ~}$

25. SANTOS, Milton. O Território e o Saber Local: algumas categorias de análise. Cadernos IPPUR (p.15-25), Ano XII, n.2, Rio de Janeiro: UFRJ, 1999b.

26. SANTOS, Milton. O Lugar: Encontrando o Futuro. Rua Revista de Arquitetura e Urbanismo, BAHIA, v. 6, p. 34-39, 1997.

27. SANTOS, Milton; SILVEIRA, Maria Laura. O Brasil: território e sociedade no início do século XXI. Rio de Janeiro: Editora Record, 2001.

28. SARTRE, Jean-Paul. (1943). II. Liberdade e Facticidade: a Situação. In: SARTRE, Jean-Paul. O ser e o nada - ensaio de ontologia fenomenológica. Petrópolis, RJ: Editora Vozes, 1997, pp.593-677.

29. SILVEIRA, Maria Laura. Uma situação geográfica: do método à metodologia. Revista Território, ano IV, n.6: p.21-28, jan/jun. 1999.

30. ZAOUAL, Hassan. O homo situs e suas perspectivas paradigmáticas. OIKOS, Rio de Janeiro, Volume 9, n. 1, pp. 13-39, 2010.

Artigo recebido em 13 de julho de 2015.

Artigo aceito em 19 de agosto de 2015. 